\title{
Morphological Description of Digestive Tract in Golden Jackal (Canis Aureus Moreoticus)
}

\author{
Florin STAN \\ Faculty of Veterinary Medicine Cluj - Napoca Department of Comparative Anatomy, University of \\ Agricultural Sciences and Veterinary Medicine, Cluj - Napoca, 3-5, Mănăștur Street, 400372, Romania. \\ * Corresponding author: flodvm@yahoo.com
}

Bulletin UASVM Veterinary Medicine 73(1) / 2016,

Print ISSN 1843-5270; Electronic ISSN 1843-5378

DOI:10.15835/buasvmcn-vm: 11411

\begin{abstract}
The Golden Jackal is continuously spreading throughout central and Eastern Europe. In Romania the living area of this specie is in Dobrogea and Danube Delta, South-Eastern Moldova, South Muntenia and Oltenia, West Plains and some areas in Central Transylvania Plateau. Surprisingly, despite its fast spreading during the last years, this species has not been of great interests for researchers. Therefore, a proper understanding of the anatomy of this species is required. Using gross dissection of four subjects, this study achieves a detailed description of anatomical particularities of the digestive tract in Golden Jackal. Given the carnivorous diet, the digestive tract anatomy of Golden Jackal is adapted to this type of nutrition. The type of dentition is dyfyodont with strong and conical crown of incisors and canines. The stomach (Gaster) is elongated without an obvious duodenal ampulla (Ampula duodeni). The descending duodenum ansa is not covered by omentum (Omentum majus). The jejunum (Jejunum) and ileon (Ileum) are long with well represented corresponding mesentery (Mesenterium). The cecum (Caecum) is small but obvious; the colon has no sacculations and low distinguishable sections, showing only a sigmoid expansion. Para-anal glands are well developed.
\end{abstract}

Keywords: digestive system, jackal, morphology

\section{INTRODUCTION}

In Romania, stable populations of Golden Jackals are found in South East of Dobrogea, in Niculitel area and in Danube plains. With high rate of reproduction, the Golden Jackal spreading is increasing and due to the aggressive behavior and farm animal's threat, the jackal became rapidly a hunted species in Romania. In these conditions, a proper morphological description in order to differentiate this species from dogs wolfs and fox is required. Nutrition strategy of this specie is important for survival and is related with the type and quality of food.

\section{AIMS AND OBJECTIVES}

The aim of the study was to describe the anatomical particularities of the digestive tract of
Golden Jackal. The results were compared with the digestive morphology of the domestic dog (Canis lupus familiaris).

\section{MATERIALS AND METHODS}

Four adult of Golden Jackals, (two male and two female), with age between 2-4 years, were dissected. The subjects were hunting harvest from Danube Delta. The Bioethics Committee of University of Agricultural Sciences and Veterinary Medicine approved the study.

\section{RESULTS AND DISCUSSION}

Dental formula was I3/3, C1/1, PM4/4, M2/3. The canines were conned and longer than in dogs and the carnassials (the last premolar in lower jaw and the first molar in the upper jaw) were well 

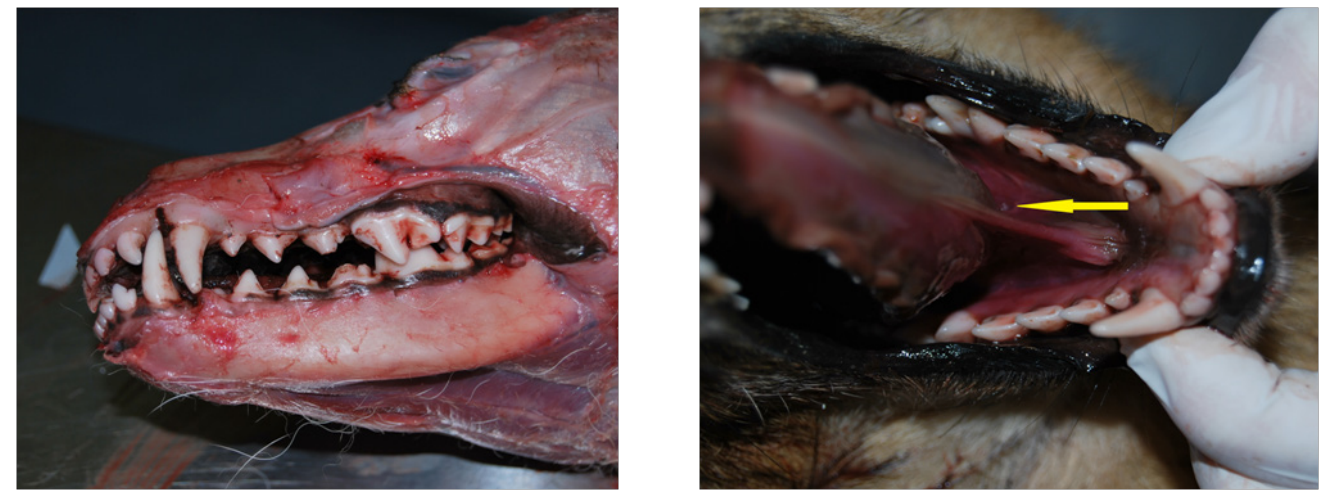

Fig. 1. The skull of the Golden jackal with strong and conned teeth - left and an obvious carunculla sublingualis - right
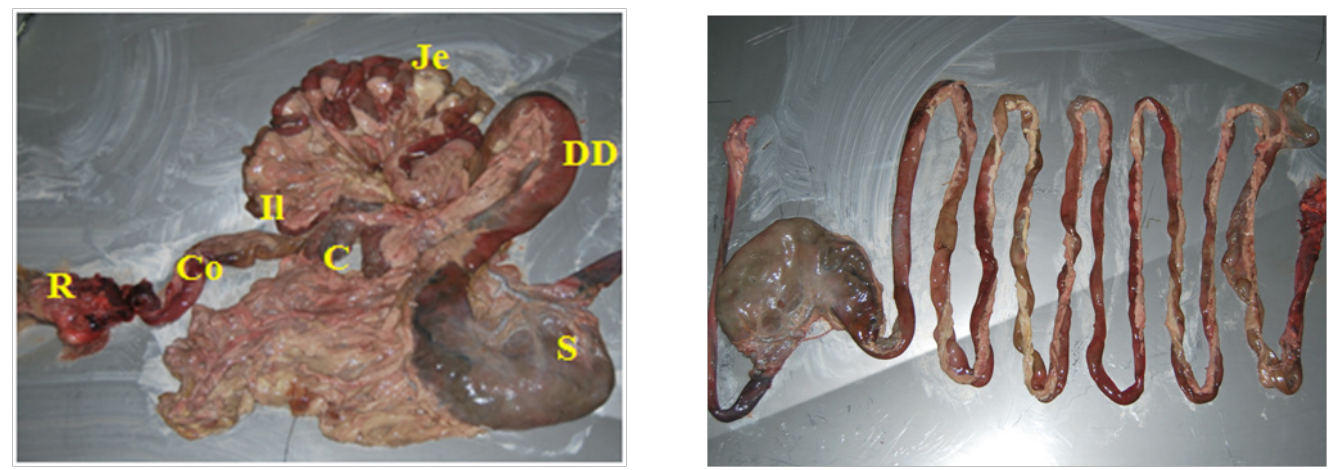

Fig.2. Digestive tract of Golden jackal. S-stomach; DD-descending duodenum; Je-jejunum; Il-ileum; C-cecum; Co-colon; R-rectum - left and absence of muscular bands or haustra - right.

developed with blade pattern (Fig.1). Due to the type of diet, the molar have grinding surfaces. The tongue was highly mobile, smooth, presents all types of lingual papillae and an obvious sublingual wattles (Caruncula sublingualis) (Fig.1). The esophagus was long, highly dilatable.

The long stomach was in relation with liver, spleen and intestinal mass showing strong and muscular pyloric antrum (Antrum pyloricum) and pyloric channel (Canalis pyloricus). The angular notch (Incisura angularis) was relatively deep compare to the small cardiac notch (Incisura cardiaca). Small intestine presents the same divisions as in dogs: duodenum, jejunum and ileum. The duodenum was long, presenting three portions: descendent ansa (Pars cranialis), caudal flexure (Flexura duodeni caudalis) and ascendant ansa (Pars ascendens).

In examined subjects no duodenal ampula (Ampula duodenalis) was present. Inside the mesoduodenum, the pancreas was visualized. Caudal flexure of the duodenum was in close proximity of pelvic cavity. The long jejunum (Jejunum) was suspended by a broad mesentery, while the ileum (Ileum) was relatively short. The ileocecal orifice was externally marked by a shallow constriction. The cecum (Caecum) was double compartmentalized without a caliber modification on the ceco-colic jonction. The colon (Colon) was very short and no muscular bands or haustra were present (Fig. 2). A small sigmoid dilatation (Colon sigmoideum) was identified. The rectum has an obvious rectal ampoule (Ampula recti) (Fig.2). Para-anal glands were well developed. The terms were consistent with NAV (Nomina Anatomica Veterinaria).

\section{Conclusion}

The entire morphology of the digestive tract in Golden Jackal is similar to that of the domestic dog.

\section{REFERENCES}

1. NAV Nomina Anatomica Veterinaria, fifth edition (2012). 